\title{
Uma nota sobre a relação entre salário mínimo e inflação no Brasil a partir de um modelo de inflação de custo e conflito distributivo *
}

\author{
Ricardo de Figueiredo Summa ${ }^{* *}$
}

\begin{abstract}
Resumo
O presente artigo busca discutir a dinâmica da inflação brasileira no período de 2000-2014 e sua relação com a política de valorização do salário mínimo, a partir de um modelo desagregado de inflação de custo. Dessa maneira, discutem-se os possíveis canais de transmissão que levariam a uma relação entre salário mínimo e inflação à luz dos dados brasileiros. Concluímos que choques no salário mínimo não produzem impacto tão significativo sobre a inflação, mas a política de valorização do salário mínimo também poderia atuar de forma indireta e influenciar a inflação. Esta última relação passa pelo efeito que a política de salário mínimo em conjunto com outras políticas institucionais e aspectos conjunturais do mercado de trabalho têm sobre a melhora de poder de barganha dos trabalhadores e do surgimento de uma inflação salarial mais resistente, a partir de 2006.
\end{abstract}

Palavras-chave: Salário mínimo; Inflação de custo; Conflito distributivo; Salários nominais; Salários reais.

\section{Abstract \\ A study on the relationship between the minimum wage and inflation in Brazil based on the inflation model of cost and distributive conflict}

In the present paper we discuss the dynamics of Brazilian inflation in the period 2000-2014 and its relation to the minimum wage policy, from the standpoint of cost-push inflation. Thus, the possible transmission channels that would lead to a relationship between the minimum wage and inflation are analyzed, evaluating the empirical plausibility of these transmission channels regarding the Brazilian data. It is concluded that the direct impact of minimum wage shocks' on inflation is limited, but the policy of minimum wage can also influence inflation in an indirect way. This indirect mechanism results from the effect that the minimum wage policy, in conjunction with other institutional policies and the labor market conditions, has on improving the bargaining power of workers and, as a consequence, the emergence of a more resilient wage inflation, since 2006.

Keywords: Minimum wage; cost-push inflation; Distributive conflict; Nominal Wages; Real wages. JEL E30, E31.

\section{Introdução}

Durante os anos 2000 foi implementada na economia brasileira uma política de valorização do salário mínimo. Mais especificamente a partir de 2007, tal política

\footnotetext{
* Artigo recebido em 30 de janeiro de 2015 e aprovado em 21 de julho de 2016.

** Professor adjunto do Instituto de Economia da Universidade Federal do Rio de Janeiro (IE-UFRJ) / Membro do Grupo de Economia Política do IE/UFRJ, Rio de Janeiro, RJ, Brasil. E-mail: rifsumma@ yahoo.com.
} 
é institucionalizada e passa a conceder o reajuste anual do salário mínimo de acordo com a inflação do ano anterior acrescida do crescimento do PIB de dois anos antes. Essa política conseguiu garantir um forte aumento real do salário mínimo e este mais que dobrou em termos reais de 2000 a 2014. Assim, muitos economistas passaram a discutir quais seriam os efeitos dessa medida para uma série de variáveis, como a desigualdade de renda e a pobreza, o impacto nas finanças públicas e na inflação (ver Barbosa; Pessoa; Moura, 2015).

O objetivo deste artigo é avaliar a relação entre a política de valorização do salário mínimo e a inflação no Brasil. A partir da perspectiva da abordagem da inflação de custo e do conflito distributivo serão avaliados (i) quais seriam os possíveis canais de transmissão do aumento do salário mínimo para a inflação dos preços no Brasil; e (ii) se estes canais de transmissão se verificaram empiricamente para o caso do Brasil nos anos 2000.

Para tanto, o artigo se articula em mais quatro seções, além desta introdução e das considerações finais. Na seção 1, apresentaremos um modelo de inflação de custo que permite avaliar os possíveis canais de transmissão do salário mínimo sobre a inflação, em um nível desagregado. A segunda seção avalia a dinâmica da inflação brasileira a partir da evolução dos itens de custo bem como os estudos que discutem a relação entre salário mínimo e inflação no Brasil. Na terceira seção avaliaremos com mais detalhes os possíveis canais de transmissão entre salário mínimo e inflação à luz dos dados da economia brasileira. Considerações finais são feitas na última seção.

\section{Um modelo de inflação de custo e conflito distributivo}

A abordagem da inflação de custo estabelece que a dinâmica dos custos de produção não está relacionada de uma forma sistemática e estável com a relação entre desvios da demanda agregada e capacidade produtiva em sua utilização plena. No caso específico do mercado de trabalho, a inflação de salários pode muito bem aparecer antes da economia alcançar uma situação de "pleno emprego". Economistas clássicos (de Smith a Marx) que acreditavam que a economia operava com desemprego estrutural destacavam, entretanto, que muitas vezes taxas de desemprego persistentemente mais baixas podiam reforçar o poder de negociação da força de trabalho, especialmente em circunstâncias políticas e institucionais favoráveis (Stirati, 1994; Kalecki, 1971; Rowthorn, 1977).

Nesta visão, a inflação salarial é entendida como uma consequência do 'excesso de demandas dos trabalhadores' em relação ao crescimento da produtividade, ao invés da visão neoclássica com mercado de trabalho competitivo 
de que esta decorreria do 'excesso de demanda por mão de obra' (Palumbo, 2015) ${ }^{1}$. Esta inflação salarial pode surgir mesmo se a economia ainda está longe do pleno emprego. Ou ainda pode não aparecer mesmo se o nível de emprego está crescendo rapidamente. Isso decorre por razões políticas ou institucionais e seus possíveis efeitos sobre a inflação salarial. Assim, a relação entre a inflação dos salários e da tendência da taxa de desemprego não é sistemática, no sentido de que choques na taxa de desemprego (ou hiato da taxa de desemprego - no sentido de desvios de uma taxa natural ou NAIRU) não têm necessariamente efeitos diretos sobre a inflação salarial, uma vez que esta relação é mediada por aspectos políticos, institucionais e culturais que influenciam o poder de negociação dos trabalhadores (Kalecki, 1971; Rowthorn, 1977; Stirati, 1994, 2001) $)^{2,3,4}$.

Alguns economistas de formação neoclássica, entretanto, se desviaram dessa visão de funcionamento do mercado de trabalho competitivo e da ideia de salários definidos como um leilão. Abba Lerner (1951), cuja obra se insere dentro do contexto da síntese neoclássica, já nos anos 50 fazia uma distinção entre o que ele chamava de uma situação de "Low Full Employment", em que é possível aumentar o número de empregos pela expansão da demanda efetiva, porém na qual o poder de barganha dos trabalhadores é alto e desencadeia uma espiral inflacionária, e o "High Full Employment", que seria o pleno emprego com escassez de trabalho, no sentido que não é possível aumentar o nível de empregos com gastos monetários adicionais.

$\mathrm{Na}$ discussão mais recente novo-keynesiana também há modelos com imperfeições no mercado de trabalho neoclássico, como sindicatos e outros aspectos que geram fontes de rigidez real no mercado de trabalho, no qual os salários podem

(1) Afinal, como vimos, na visão da economia política clássica na qual pode existir desemprego estrutural permanente, se os salários reais fossem determinados por um processo de leilão e a diminuição salarial não fosse capaz de gerar aumento na demanda por trabalho, a consequência é que os salários reais cairiam a zero. (Garegnani, 1990). Por isso, segundo esta visão teórica o nível e evolução dos salários nominais têm que ser determinado por outros fatores que não a oferta e demanda pro trabalho, tais como fatores políticos, institucionais e culturais (Stirati, 1994).

(2) Somado às condições estruturais e conjunturais da situação do mercado de trabalho discutidas acima, outros fatores também influenciam o poder de barganha dos trabalhadores, como, por exemplo, a política de salário mínimo, o poder dos sindicatos, a legislações de proteção trabalhista, etc.

(3) Mesmo Phillips (1958) em seu trabalho seminal chama a atenção para o fato que tanto o nível quanto a mudança na taxa de desemprego pode ser importante para explicar o crescimento dos salários. Níveis mais baixos de desemprego geram uma maior concorrência entre os empregados, aumentando os salários nominais. Por outro lado, reduções na taxa de desemprego (a taxa de variação da taxa de desemprego) aumenta o poder de barganha dos trabalhadores e os coloca numa posição mais forte para exigir aumentos salariais (Pollin, 2003; Palumbo, 2015). Além disso, a persistência parece relevante uma vez que, em períodos em que a taxa de desemprego é mantida elevada por um longo período, isso diminui o poder de barganha dos trabalhadores através do "efeito de disciplina" (Kalecki, 1943).

(4) Para análises empíricas sobre a inflação salarial nos países centrais utilizando esse arcabouço, ver Glyn, (2007) e Garegnani, Cavaliere e Lucii (2008). 
subir antes do pleno emprego ${ }^{5}$, bem como modelos com aspiração salarial (Ball; Moffit, 2001) em que ganhos de produtividade não são repassados no curto prazo para os salários, e assim não haveria inflação salarial mesmo com a economia em situação de pleno emprego ${ }^{6}$.

Nesse artigo utilizaremos o modelo de inflação desagregada baseada na abordagem da inflação de custo e conflito distributivo. Este tipo de modelagem segue uma tradição bastante difundida na década de 80 (Syllos-Labini, (1979, 1984), inclusive no Brasil, por um grupo de economistas da PUC-RJ (Lara Rezende; Lopes, 1981), Modiano, $(1983,1985)^{7}$, mas que ultimamente foi abandonada e substituída pela discussão da estimação da forma reduzida das equações de inflação.

A maneira de construir esses modelos parte de alguma desagregação do índice geral de preços, cuja variação dos índices desagregados de preços são contabilmente explicados por variações no custo variável e no mark-up. A partir daí algumas suposições são feitas sobre os principais fatores de variação do custo de produção dos setores e de variáveis explicativas para a mudança no mark-up.

Para o nosso propósito de avaliar a inflação brasileira e sua relação com o salário mínimo, partiremos da desagregação do Índice geral de preços $(P)$ em preços monitorados $\left(P_{m}\right)$ e livres, em que estes últimos podem ainda ser divididos em preços dos produtos industriais $\left(P_{I}\right)$, dos alimentos $\left(P_{A}\right)$ e dos serviços $\left(P_{S}\right)$, em que a,b,c e $\mathrm{d}$ correspondem aos pesos dos índices desagregados no índice geral:

$$
\text { (1) } \quad P_{t}=P_{I, t}^{a} P_{A, t}^{b} P_{S, t}^{c} P_{M, t}^{d}
$$

Aplicando o logaritmo $\ln$ em ambos os lados, temos uma equação para a relação entre inflação do IPCA e seus componentes segundo a desagregação discutida:

$$
\text { (2) } \pi_{t}=a \pi_{t}^{I}+b \pi_{t}^{A}+c \pi_{t}^{S}+d \pi_{t}^{M} \operatorname{com} \mathrm{a}+\mathrm{b}+\mathrm{c}+\mathrm{d}=1
$$

A inflação dos monitorados segue um esquema de indexação à inflação agregada passada (medida pelo IPCA). Além disso, tem uma sensibilidade à inflação importada em R\$, que é medida pela taxa de variação da inflação importada em US\$ e da taxa de variação da taxa de câmbio nominal $\left(\pi^{*}+\hat{e}\right)$, uma vez que parte dos contratos está vinculada total ou parcialmente ao IGP, e uma parte considerável desse índice é composta pelo Índice de Preços do Atacado (IPA), bastante sensível à

(5) Ver Carlin e Soskice (2005) para uma apresentação desses modelos e Aidar (2012) e Stirati (2015) para uma avaliação crítica.

(6) No nível micro, A relação entre nível de salários e nível de atividade foi encontrada por Blanchflower e Oswald (2005) no que ficou conhecida como "curva de salários". Para uma aplicação das curvas de salário para a análise da economia brasileira, ver Amitrano (2015).

(7) Para uma discussão teórica destes modelos ver também Bresser Pereira (1984) e Serrano (1986) e para uma avaliação histórica destes modelos ver Bresser Pereira (2010) e Serrano (2010). 
inflação importada em R\$. Além disso, incluímos um componente autônomo relacionado à política do governo $\left(a_{0 t}\right)$ :

$$
\pi_{t}^{M}=a_{0 t}+\alpha_{1} \pi_{t-1}+\alpha_{2}\left(\pi^{*}+\hat{e}\right)_{t-1}
$$

Com relação aos produtos industriais, vamos supor que parte deles é comercializável e parte não-comercializável. A parcela não-comercializável dos produtos industriais $\left(\theta_{I}\right)$ dependerá da variação do custo variável $\left({\widehat{C_{v}}}_{t}{ }^{I}\right)$ e do markup da indústria $\left(\hat{\mu}_{t}^{I}\right)$. A parte comercializável, por sua vez, segue a inflação importada em R \$, pois o reajuste dos preços dos produtos comercializáveis não pode se descolar, por meio da concorrência internacional, da variação dos preços dos produtos importados e exportáveis medidos na moeda doméstica:

$$
\text { (4) } \pi_{t}^{I}=\theta_{I}\left(\hat{\mu}_{t}^{I}+{\widehat{C_{v_{t}}}}^{I}\right)+\left(1-\theta_{I}\right)\left(\pi^{*}+\hat{e}\right)_{t-1}
$$

Vamos supor inicialmente que o mark-up possa ser sensível ao hiato do produto $\left(Y-Y^{*}\right)$, no sentido que as indústrias que produzem bens não comercializáveis consigam aumentar suas margens quando a economia está aquecida. Ou seja, quando o produto agregado $Y$ se encontra acima do produto potencial, $Y^{*}$ :

$$
\text { (5) } \hat{\mu}^{I}=\left(\vartheta^{I}{ }_{0}\right)\left(Y-Y^{*}\right)
$$

Com relação ao custo variável da indústria, a taxa de variação destes dependem da relação entre a variação dos salários nominais pagos pela indústria e a variação da produtividade industrial $\left(\widehat{W}_{t}^{I}-\hat{\rho}_{t}^{I}\right.$ ), da variação do custo dos insumos importados medidos em moeda doméstica, da variação dos preços monitorados utilizados no processo de produção e dos custos de financiamento, $\Delta i$ :

$$
\begin{gathered}
(6) \widehat{C}_{v_{t}}{ }^{I}=\beta_{1}\left(\widehat{W}_{t}^{I}-\hat{\rho}_{t}^{I}\right)+\beta_{2}\left(\pi^{*}+\hat{e}\right)_{t-1}+\beta_{3} \pi_{t-1}^{M}+\beta_{4} \Delta i, \operatorname{com} \beta_{1}+\beta_{2}+\beta_{3}+ \\
\beta_{4}=1
\end{gathered}
$$

A variação dos salários nominais industriais é reajustada de acordo com a inflação agregada passada, com o hiato da taxa de desemprego $\left(D_{t}-D_{t}^{*}\right)$ e com variações do salário mínimo, $\widehat{W}_{\min _{t-1}}$, além de um componente tendencial autônomo que reflete a capacidade de barganha dos trabalhadores em conseguir aumentos acima da inflação:

$$
\text { (7) } \widehat{W}_{t}^{I}=\omega^{I}{ }_{0 t}+\omega^{I}{ }_{1} \pi_{t-1}-\omega^{I}{ }_{2}\left(D_{t}-D_{t}^{*}\right)+\omega^{I}{ }_{3} \widehat{W}_{\text {min }_{t-1}}
$$

Dessa maneira, a relação entre salário mínimo e inflação depende do impacto do salário mínimo sobre os salários da indústria, e do repasse destes aos preços, que ocorre no caso dos bens industriais que não estão sujeitos à concorrência externa.

Com relação à inflação dos alimentos, supomos novamente que uma parcela é comercializável e outra não comercializável. A parte não comercializável depende 
da variação do mark-up e da variação dos custos variáveis do setor produtor de alimentos (agricultura e indústria) enquanto a parte comercializável segue a inflação importada em $\mathrm{R} \$$ :

$$
\text { (8) } \pi_{t}^{A}=\theta_{A}\left(\hat{\mu}_{t}^{A}+{\widehat{C_{v_{t}}}}^{A}\right)+\left(1-\theta_{A}\right)\left(\pi^{*}+\hat{e}\right)_{t-1}
$$

Supondo que o mark-up dos alimentos é sensível ao hiato do produto $\left(Y-Y^{*}\right)$, no sentido de que o setor produtor de alimentos não-comercializáveis consiga aumentar (diminuir) suas margens quando a economia está aquecida (desaquecida) ou seja, quando o produto agregado $Y$ está acima do produto potencial, $Y^{*}$ :

$$
\text { (9) } \hat{\mu}^{A}=\left(\vartheta_{0}^{A}\right)\left(Y-Y^{*}\right)
$$

Os custos variáveis da atividade produtora de alimentos variam segundo a variação dos salários nominais descontada a produtividade da atividade produtora de alimentos, dos custos dos insumos importados medidos em moeda doméstica, da inflação dos preços monitorados utilizados no processo de produção de alimentos, da variação do custo dos fretes $\widehat{F r}$, além do efeito de quebras de safras agrícolas $\varepsilon_{A}$.

$$
\text { (10) }{\widehat{C_{v_{t}}}}^{A}=\gamma_{1}\left(\widehat{W}_{t}^{A}-\hat{\rho}_{t}^{A}\right)+\gamma_{2}\left(\pi^{*}+\hat{e}\right)_{t-1}+\gamma_{3} \pi_{t-1}^{M}+\gamma_{4} \widehat{F r}_{t-1}+\gamma_{5} \varepsilon_{A t}
$$

$\operatorname{com} \gamma_{1}+\gamma_{2}+\gamma_{3}+\gamma_{4}+\gamma_{5}=1$

A variação dos salários nominais da atividade produtora de alimentos depende de como os salários são reajustados de acordo com a inflação agregada passada, com o hiato da taxa de desemprego $\left(D_{t}-D_{t}^{*}\right)$ e com variações do salário mínimo, $\widehat{W}_{\min _{t-1}}$, além de um componente tendencial autônomo que reflete a capacidade de barganha dos trabalhadores em conseguir aumentos acima da inflação:

$$
\text { (11) } \widehat{W}_{t}^{A}=\omega^{A}{ }_{0}+\omega^{A}{ }_{1} \pi_{t-1}-\omega^{A}{ }_{2}\left(D_{t}-D_{t}^{*}\right)+\omega^{A}{ }_{3} \widehat{W}_{\text {min }_{t-1}}
$$

Dessa maneira, a relação entre salário mínimo e inflação dos alimentos depende do impacto do salário mínimo sobre os salários pagos na produção de alimentos, e do repasse destes aos preços, que ocorre no caso dos alimentos que não estão sujeitos à concorrência externa.

Vamos supor por fim que os serviços são não-comercializáveis. Assim, a inflação dos serviços dependerá da variação do mark-up e dos custos variáveis do setor. Porém, como por motivos relacionados à própria construção do índice de preços ao consumidor do Brasil, uma parte dos preços dos serviços refletem diretamente os salários e estes seguem muito de perto o salário mínimo (por ex. emprego doméstico), vamos supor que uma parte da inflação de serviço com peso $\left(1-\theta_{S}\right)$ está diretamente ligada a evolução do salário mínimo.

$$
\text { (12) } \pi_{t}^{S}=\theta_{S}\left(\hat{\mu}_{t}^{S}+{\widehat{C_{v}}}_{t}^{S}\right)+\left(1-\theta_{S}\right) \widehat{W}_{\min _{t-1}}
$$


Vamos supor inicialmente que o mark-up possa ser sensível ao hiato do produto $\left(Y-Y^{*}\right)$, no sentido de que as empresas do setor de serviços consigam aumentar suas margens quando a economia está aquecida. Ou seja, quando o produto agregado $Y$ está acima do produto potencial, $Y^{*}$ :

$$
\text { (13) } \hat{\mu}_{t}^{S}=\left(\vartheta^{S}{ }_{0}\right)\left(Y-Y^{*}\right)
$$

Com relação ao custo variável do setor serviços, estes dependem da relação entre a variação dos salários nominais pagos pelo setor serviços e a variação da produtividade dos serviços $\left(\widehat{W}_{t}^{I}-\hat{\rho}^{I}{ }_{t}\right)$, da variação do custo dos insumos importados medidos em moeda doméstica e da variação dos preços monitorados que entram como custo no setor serviços:

$$
\text { (14) }{\widehat{C_{v_{t}}}}^{S}=\delta_{1}\left(\widehat{W}_{t}^{S}-\hat{\rho}_{t}^{S}\right)+\delta_{2}\left(\pi^{*}+\hat{e}\right)+\delta_{3} \pi_{t-1}^{M}
$$

A variação dos salários nominais do setor serviços depende de como os salários são reajustados de acordo com a inflação agregada passada, com o hiato da taxa de desemprego $\left(D_{t}-D_{t}^{*}\right)$ e com variações do salário mínimo, $\widehat{W}_{\min _{t-1}}$, além de um componente tendencial autônomo que reflete a capacidade de barganha dos trabalhadores em conseguir aumentos acima da inflação:

$$
\text { (15) } \widehat{W}_{t}^{S}=\omega^{S}{ }_{0}+\omega^{S}{ }_{1} \pi_{t-1}-\omega^{S}{ }_{2}\left(D_{t}-D_{t}^{*}\right)+\omega^{S}{ }_{3} \widehat{W}_{\min _{t-1}}
$$

Assim, os serviços apresentam duas características diferentes com relação aos bens industriais e alimentos: primeiro, uma parte dos serviços é afetada diretamente pelo salário mínimo, enquanto a outra parte é afetada via efeito do salário mínimo sobre os custos salariais dos serviços (assim como os bens industriais e alimentos); segundo, como os serviços não estão sujeitos a concorrência externa e o peso do custo salarial sobre o preço dos serviços é maior que nos outros setores aqui analisados, é de se esperar um repasse maior dos salários dos serviços para a inflação de serviços. Estes dois fatores somados nos permite entender as razões para a inflação de serviços ser mais sensível à política de salário mínimo do que os outros setores.

Por fim, para deixarmos todas as pressões de demanda em termos do hiato do produto, utilizamos uma equação para a Lei de Okun, ligando o hiato de desemprego com o hiato de produto:

$$
\text { (16) }\left(D_{t}-D_{t}^{*}\right)=\epsilon\left(Y-Y^{*}\right)
$$

Substituindo as variáveis explicativas nas equações desagregadas de inflação, chegamos nas formas reduzidas das equações de inflação dos monitorados, 
dos produtos industriais, dos alimentos e serviços que irão depender da inércia, da inflação importada em $\mathrm{R} \$$ e das pressões de demanda ${ }^{8}$ :

$$
\begin{gathered}
\text { (17) } \pi_{t}^{M}=a_{0 t}+\alpha_{1} \pi_{t-1}+\alpha_{2}\left(\pi^{*}+\hat{e}\right)_{t-1} \\
\text { (18) } \pi_{t}^{I}=C_{I}+A_{I 1} \pi_{t-1}+A_{I 2} \pi_{t-2}+B_{I 1}\left(\pi^{*}+\hat{e}\right)_{t-1}+B_{I 2}\left(\pi^{*}+\hat{e}\right)_{t-2}- \\
C_{I} \hat{\rho}_{t}^{I}+D_{I} \widehat{W}_{\text {min }_{t-1}}+F_{I}\left(Y-Y^{*}\right)_{t} \\
\text { (19) } \pi_{t}^{A}=C_{A}+A_{A 1} \pi_{t-1}+A_{A 2} \pi_{t-2}+B_{A 1}\left(\pi^{*}+\hat{e}\right)_{t-1}+B_{A 2}\left(\pi^{*}+\hat{e}\right)_{t-2}- \\
C_{A} \hat{\rho}_{t}^{A}+D_{A} \widehat{W}_{\text {min }_{t-1}}+F_{A}\left(Y-Y^{*}\right)_{t} \\
\text { (20) } \pi_{t}^{S}=C_{S}+A_{S 1} \pi_{t-1}+A_{S 2} \pi_{t-2}+B_{S 1}\left(\pi^{*}+\hat{e}\right)_{t-1}+B_{S 2}\left(\pi^{*}+\hat{e}\right)_{t-2}- \\
C_{S} \hat{\rho}_{t}^{S}+\left(c\left(1-\theta_{S}\right)+D_{S}\right) \widehat{W}_{\text {min }_{t-1}}+F_{S}\left(Y-Y^{*}\right)_{t}
\end{gathered}
$$

Substituindo (17) a (20) em (2) chegamos à equação agregada da inflação:

$$
\begin{gathered}
\text { (21) } \pi_{t}=C_{0}+\psi_{t}+A_{1} \pi_{t-1}+A_{2} \pi_{t-2}+B_{1}\left(\pi^{*}+\hat{e}\right)_{t-1}+B_{2}\left(\pi^{*}+\hat{e}\right)_{t-2}- \\
C \rho+\left(X+c\left(1-\theta_{S}\right)\right) \widehat{W}_{\min _{t-1}}+F\left(Y-Y^{*}\right)_{t}
\end{gathered}
$$

$$
\text { Com: } X=a \theta_{I} \beta_{1} \omega_{3}^{I}+b \theta_{A} \gamma_{1} \omega_{3}^{A}+c\left(\theta_{S} \delta_{1} \omega^{S}{ }_{3}\right) \text { e } \psi_{t}=a \theta_{I} \beta_{1} \omega^{I} 0 t+
$$$$
b \theta_{A} \gamma_{1} \omega^{A}{ }_{0 t}+c \theta_{S} \delta_{1} \omega^{S}{ }_{0 t}
$$

Assim, a inflação de longo prazo dependerá do grau de inércia, $1-A_{1}-A_{2}$; da inflação importada e seus efeitos diretos sobre os bens industriais e alimentos tradables, sobre os preços monitorados e sobre o custo dos bens industriais, alimentos e serviços non tradables; do hiato do produto e das variáveis autônomas como as políticas de reajuste dos preços monitorados; dos ganhos de produtividade $\rho$; e da variação do salário mínimo e seu efeito direto sobre uma parte dos serviços e efeito indireto pelo impacto sobre os salários dos bens non tradables industriais e alimentos e dos serviços e de uma variável que capta o grau do poder de barganha dos trabalhadores em negociar seus salários com ganhos reais, $\psi_{t}$, independente da situação de aquecimento ou não do mercado de trabalho.

$$
\text { (22) } \pi_{t}=\frac{C_{0}}{1-A_{1}-A_{2}}+\frac{\psi_{t}}{1-A_{1}-A_{2}}-\frac{C \rho}{1-A_{1}-A_{2}}+\frac{X+c\left(1-\theta_{S}\right)}{1-A_{1}-A_{2}} \widehat{W}_{\min _{t-1}}+
$$

\subsection{Introduzindo uma regra de reajuste do salário mínimo no modelo}

Para entender como a regra de reajuste de salário mínimo pode ser incorporada e seus efeitos sobre a inflação, vamos utilizar a regra de reajuste de

(8) Nas equações (18) a (20) os parâmetros $A_{i 1}$ levam em conta o efeito dos salários sobre a inflação em cada setor (no caso depende de quanto os salário dependem da inflação defasada, do quanto os custos variáveis dependem dos salários e qual a proporção de bens tradables em cada setor. Os parâmetros $A_{i 2}$ levam em conta o efeito dos preços monitorados defasados que entram como componente de custo em cada setor. Os parâmetros $B_{i 1}$ e $B_{i 2}$ levam em conta os efeitos direto e indireto da inflação dos bens tradables sobre a inflação do setor enquanto os parâmetros $F_{i}$ levam em conta todos os efeitos de pressões de demanda sobre a inflação setorial. Na equação (21) os parâmetros A, B e F são decorrentes da soma dos parâmetros das equações desagregadas. 
maneira mais geral, na qual a variação do salário mínimo é igual à inflação passada e adicionado por uma variável de escolha política $\sigma_{0 t}$ (que pode ser o crescimento do PIB, da produtividade, do PIB per capita, do salário médio ou mesmo uma variável política exógena), cujo objetivo é proporcionar ganhos reais para o salário mínimo (Martinez e Braga, 2012):

$$
\text { (23) } \widehat{W}_{\min _{t}}=\sigma_{0 t}+\sigma_{1} \pi_{t-1}
$$

Incorporando (23) em (22) teríamos:

$$
\text { (24) } \begin{aligned}
\pi_{t}= & \frac{C_{0}}{1-A_{1}-A_{2}^{*}}+\frac{\psi_{t}}{1-A_{1}-A_{2}^{*}}-\frac{C \rho}{1-A_{1}-A_{2}^{*}}+\frac{X+c\left(1-\theta_{S}\right)}{1-A_{1}-A_{2}^{*}} \sigma_{0 t}+ \\
& \frac{B_{1}\left(\pi^{*}+\hat{e}\right)_{t-1}+B_{2}\left(\pi^{*}+\hat{e}\right)_{t-2}}{1-A_{1}-A_{2}^{*}}+\frac{F\left(Y-Y^{*}\right)}{1-A_{1}-A_{2}^{*}}
\end{aligned}
$$

Nesse caso, como podemos ver pela equação 24 , uma regra de reajuste do salário mínimo por um lado aumenta o grau de inércia (aumentando $A_{2}^{*}$ ) e assim a inflação de longo prazo da economia. Por outro, o componente de variação real de reajuste do mínimo $\sigma_{0 t}$ também aumenta a inflação de longo prazo, na proporção $X+c\left(1-\theta_{S}\right)$ que inclui tanto o impacto do salário mínimo nos salários de bens industriais e agrícolas non tradables e do salário dos serviços, quanto do impacto direto do salário mínimo sobre alguns preços finais de serviços.

Aqui podemos resumir esquematicamente os possíveis canais de transmissão da variação do salário mínimo sobre a inflação:

1. O possível efeito de choques do salário mínimo sobre a demanda agregada e o nível do produto, que ao operar acima do produto potencial levaria a pressões inflacionárias.

2. O possível efeito de choques do salário mínimo afetar diretamente preços de serviços livres realizados por trabalhadores de qualificação mais baixa e com remuneração muito relacionada ao salário mínimo.

3. O possível efeito da política de valorização do salário mínimo afetar o crescimento dos salários da economia.

\section{Um panorama sobre a Inflação de custo no Brasil e a relação entre inflação e salário mínimo}

Nesta seção vamos avaliar a dinâmica da inflação brasileira e de seus componentes de custo em três subperíodos distintos. Conforme se observa na Tabela 1, a inflação foi mais alta em 2000-03 (8,8\%), caindo para uma média de 5,2\% em 2004-2009 e subindo um pouco para uma média de 6,1\% de 2010-2014. 
Tabela 1

Inflação e variação dos componentes de custo

\begin{tabular}{|c|c|c|c|c|c|}
\hline & Média & $2000-2003$ & 2004-2009 & $2010-2014$ & 2000-2014 \\
\hline \multirow{5}{*}{ Inflação de Preços } & Alimentos & $14,2 \%$ & $4,9 \%$ & $8,4 \%$ & $8,1 \%$ \\
\hline & Industrializados & $7,9 \%$ & $3,9 \%$ & $3,5 \%$ & $4,7 \%$ \\
\hline & Serviços & $7,2 \%$ & $6,5 \%$ & $8,8 \%$ & $7,3 \%$ \\
\hline & Monitorados & $12,1 \%$ & $5,3 \%$ & $4,0 \%$ & $6,9 \%$ \\
\hline & IPCA & $8,8 \%$ & $5,2 \%$ & $6,1 \%$ & $6,4 \%$ \\
\hline \multirow{5}{*}{ Inflação de Salários } & Salário Total & $2,9 \%$ & $8,4 \%$ & $8,9 \%$ & $7,4 \%$ \\
\hline & $\begin{array}{c}\text { Indústria de } \\
\text { transformação }\end{array}$ & $4,1 \%$ & $8,9 \%$ & $8,9 \%$ & $7,8 \%$ \\
\hline & Serviços & $-0,1 \%$ & $7,3 \%$ & $8,3 \%$ & $6,0 \%$ \\
\hline & Agropecuária & $5,7 \%$ & $9,8 \%$ & $10,4 \%$ & $10,7 \%$ \\
\hline & Salário mínimo & $16,0 \%$ & $12,3 \%$ & $9,5 \%$ & $12,5 \%$ \\
\hline \multirow{3}{*}{ Produtividade } & $\begin{array}{c}\text { Indústria de } \\
\text { transformação }\end{array}$ & $2,2 \%$ & $3,4 \%$ & $-0,8 \%$ & $1,6 \%$ \\
\hline & Serviços & $-0,9 \%$ & $1,3 \%$ & $2,4 \%$ & $0,9 \%$ \\
\hline & Agropecuária & $7,1 \%$ & $3,0 \%$ & $8,6 \%$ & $5,1 \%$ \\
\hline \multirow{3}{*}{ Inflação Importada } & $\begin{array}{l}\text { Commodities } \\
\text { (IBC-Br) }\end{array}$ & $20,4 \%$ & $1,5 \%$ & $6,8 \%$ & $8,1 \%$ \\
\hline & Importações & $20,3 \%$ & $0,8 \%$ & $4,3 \%$ & $6,7 \%$ \\
\hline & Exportações & $18,7 \%$ & $4,6 \%$ & $9,2 \%$ & $8,3 \%$ \\
\hline
\end{tabular}

1) A inflação geral do IPCA / IBGE; (2) Os preços de inflação monitorado a partir BCB; (3) "Alimentos e Bebidas", "produtos industriais" e "serviços" de inflação de Martinez (2014) (série temporal vai até dezembro 2013.); (4) salários nominais de MTE /CAGED, salário nominal médio (de admissão e desligamento) (série temporal vai até dezembro 2013.); (5) o salário mínimo nominal do MTE; (6) Agricultura e Serviços: produtividade da economia do SCN / IBGE, calculado como Valor Adicionado/trabalhadores empregados, deflacionados pelo deflatores setoriais (Fevereiro; Freitas, 2015) (dados até 2011); (7) produtividade da indústria de transformação calculado como a produção física da indústria de transformação (PIM / IBGE) dividido pelas horas trabalhadas na indústria (PIMES / IBGE); (8) IC-Br do BCB; (9) Inflação de importação e exportação em R\$ calculado como inflação de importação e exportação em US\$ da Funcex vezes a variação da taxa de câmbio nominal (BCB);

Olhando para a inflação salarial, notamos uma grande diferença do primeiro período com uma inflação salarial baixa (bem abaixo da inflação) em relação aos dois períodos seguintes, quando a inflação salarial se inicia em 2006 e passa a ficar mais resistente no último período. Do ponto de vista da inflação importada em $\mathrm{R}$ \$ (que consiste na variação da multiplicação de um índice de preços internacional em dólares pela taxa de câmbio nominal) notamos um comportamento de alta inflação nos períodos 2000-2003 e 2010-2014, o que ajuda a inflação média a ficar 
mais alta. No período 2004-2009, em que a média da inflação ficou baixa, o que se observa é que a inflação importada (em R\$) ficou abaixo da inflação. Esse efeito era mais disseminado para os bens industriais, alimentos e monitorados em 2000-03, quando os monitorados passam a ficar menos relacionados com a inflação importada a partir do período seguinte. Para o período 2010-14 notamos que mesmo com o crescimento mais forte da inflação importada (em $\mathrm{R} \$$ ), a inflação dos bens industrializados segue baixa, e a pressão maior recai sobre a inflação dos alimentos. Por fim, a dinâmica dos preços administrados também foi bastante distinta, com estes subindo mais que a inflação no primeiro período, igual à inflação no segundo período e menor que inflação no terceiro período 9 .

Dessa maneira, a partir dos dados apresentados podemos concluir que a inflação mais alta do período 2000-2003 foi decorrente tanto de uma inflação importada (em R\$) mais forte e de uma inflação dos monitorados (que eram muito vinculados ao IGP_M no período), ao passo que a inflação salarial ficou bem abaixo da inflação dos preços no período, o que colaborou para a inflação dos preços não ser ainda maior. No período seguinte, 2004-2009, a inflação média ficou mais baixa, decorrente tanto de uma inflação menor dos preços administrados quanto de uma menor inflação importada (em $\mathrm{R} \$$ ) decorrente do processo de valorização da taxa de câmbio nominal do período. O que colaborou para aumentar a inflação dos preços foi o começo da inflação salarial em 2006, pelos motivos discutidos nas seções anteriores. Por fim, no último período, que apresenta uma média inflacionária um pouco mais alta que a do período anterior, tivemos uma inflação salarial (com seus impactos mais fortes sobre os serviços livres) somada a uma inflação importada (em $\mathrm{R}$ ) mais forte, que só não foi mais alta pelo forte controle da inflação dos bens e serviços monitorados.

Apenas olhando para os dados divididos nessa periodização, não observamos uma relação tão clara entre o comportamento do salário mínimo, dos salários médios e dos preços ao consumidor (IPCA). Enquanto o reajuste nominal do salário mínimo foi diminuindo de $16 \%$ para $12,3 \%$ e $9,5 \%$, o crescimento dos salários nominais foi aumentando de $2,9 \%$ para $8,4 \%$ e $8,9 \%$, ao passo que a inflação foi mais alta no primeiro período $(8,8 \%)$, caindo no segundo período $(5,2 \%)$ e subindo no terceiro período $(6,1 \%)$.

Do ponto de vista dos estudos empíricos aplicados ao Brasil, temos poucos exercícios econométricos que avaliam o impacto de uma variação do salário mínimo sobre a inflação ${ }^{10}$. Em um estudo utilizando dados em painel até o ano 2000, Lemos

(9) Esse resultado foi decorrente de uma série de mudanças contratuais nos anos de 2005 e 2006 que passaram a ser menos sensíveis ao IGP-M e, por conseguinte, da inflação importada (em R \$), bem como da política da Petrobras de controle de gasolina e óleo diesel (Martinez; Cerqueira, 2013) e das políticas de controle mais direto do preço da energia a partir de 2011.

(10) Para os EUA, por exemplo, existe uma série de estudos utilizando diferentes metodologias para avaliar o impacto de aumentos de salário mínimo sobre a inflação. Para um survey ver Lemos (2008). Nesse survey ela mostra que em geral $10 \%$ de aumento do salário mínimo aumenta o IPC em não mais que $0.4 \%$. 
(2005) mostra que no Brasil um aumento de $10 \%$ do salário mínimo aumenta o IPCA em $0.8 \%$. Um estudo do Bacen (2013) utilizando dados mais recentes mostra que o aumento de $10 \%$ no salário mínimo tem um impacto máximo na inflação de serviços de $0,6 \%$ e no IPCA de $0,3 \%$.

Braga (2013) tenta estimar o impacto do salário mínimo sobre a inflação, mas não consegue obter um resultado significativo. Braga (2013) porém mostra graficamente que a inflação de serviços acompanha com algum desconto a variação do salário mínimo.

Borges (2015) estima um modelo VAR para o período 2000-2013 e mostra que os reajustes do salário mínimo têm impacto estatisticamente não significante sobre a inflação ao consumidor (considerando a ordem de grandeza dos reajustes colocados em prática desde 2000, p.280) ${ }^{11}$. Parara a inflação dos serviços, o impacto calculado de reajustes do salário mínimo é positivo e estatisticamente significativo.

Botelho (2015) desagrega a inflação de serviços em cinco grupos ${ }^{12}$, e encontra que o único subgrupo que tem correlação com a inflação é o chamado "serviços intensivos em mão-de-obra sem ensino superior (Simo)". O autor estima um modelo VEC para cada um dos itens deste subgrupo "Simo" e a conclusão é que uma elevação em $1 \%$ no salário mínimo tem impacto em 0,028 ponto percentual sobre a taxa de inflação do IPCA acumulada em 12 meses. A conclusão do autor é que a política de salário mínimo não é "relevante para entender a deterioração da perspectiva inflacionária da economia brasileira dos últimos anos (p. 256)". Dessa maneira, a conclusão desses estudos sugere que o repasse do salário mínimo sobre a inflação, quando existente, tem uma elasticidade bastante baixa.

\section{Um olhar mais detalhado para os canais de transmissão do salário mínimo para a inflação no Brasil}

Vejamos agora em detalhes quais seriam os possíveis canais de transmissão do salário mínimo para a inflação, discutidos no modelo apresentado na seção 1, e se estes fazem sentido tendo em vista a experiência recente da economia brasileira.

O primeiro efeito do possível canal de transmissão de choques do salário mínimo sobre a demanda agregada seria decorrente do crescimento do consumo privado, devido aos ganhos da massa salarial e das transferências públicas bastante vinculadas ao salário mínimo (Orair; Gobetti, 2010; Dos Santos, 2013). Para tanto, os choques de salário mínimo teriam que impactar a demanda agregada significativamente para, ao colocar a economia acima do produto potencial, gerar pressões inflacionárias. Em nossa equação (24) esse canal de transmissão seria captado pelo termo $F\left(Y-Y^{*}\right)$.

(11) Nesse modelo, o autor incorpora tanto o hiato do produto quanto as expectativas de inflação.

(12) Os subitens são "alimentação fora do domicilio", "aluguel", "serviços profissionais", "serviços intensivos em mão-de-obra sem ensino superior" e "outros serviços". 
Esse tipo de canal de transmissão não parece muito provável por uma série de motivos. Primeiro, ainda que o salário mínimo tenha sido importante para o crescimento das transferências (Orair; Gobetti, 2010) e, um pouco menos importante, para o crescimento da massa salarial (Medeiros, 2015b), o crescimento da demanda agregada da economia brasileira foi influenciado também por uma série de outras políticas e condições, como a expansão do crédito, os investimentos públicos e das estatais, a política de valorização dos salários do funcionalismo público, as políticas de expansão do investimento residencial, além do crescimento exógeno das exportações e o próprio investimento privado induzido pelo ritmo mais forte de crescimento da demanda agregada (Serrano; Summa, 2012, 2015; Dos Santos, 2013). Sendo assim, é difícil dizer que o aumento do salário mínimo tenha sido o protagonista para o crescimento da demanda agregada na economia brasileira dos anos 2000 para frente.

Além disso, mesmo supondo que o salário mínimo fosse bastante importante para explicar o crescimento da demanda agregada, para os dados brasileiros é difícil encontrar uma relação estável entre hiato do produto - que mediria o aquecimento no mercado de bens e serviços - e a inflação ${ }^{13}$.

Passando da análise agregada para a desagregada, notamos que a cesta de consumo das famílias que ganham até dois salários mínimos ${ }^{14}$, percebemos que esta se concentra na compra de alimentos (principalmente em domicílio) ${ }^{15}$, bens eletroeletrônicos e bens monitorados como medicamentos, gás, energia elétrica, plano de saúde e transporte público (Medeiros, 2015a). Os alimentos no domicílio, com forte componente de bens tradable (85\% segundo Martinez, (2014) não apresentam relação clara entre demanda e inflação ${ }^{16}$. Os bens industriais, também bastante tradables e com forte concorrência externa são os que apresentam inflação mais moderada recentemente (média de 3,7\% de 2004-2013). Por fim, os bens e serviços monitorados pelo governo não reagem a pressões de demanda ${ }^{17}$.

(13) Ver Summa e Macrini (2014) e Summa (2011) para um survey dos estudos empíricos da inflação brasileira. Estas relações também são difíceis de encontrar mesmo no nível desagregado (Braga, 2013; Summa; Braga, 2014; Bastos; Jorge; Braga, 2015).

(14) Aqui estamos pegando famílias que podem ser formadas por dois membros que ganham um salário mínimo cada.

(15) Doria (2013) mostra que famílias com renda equivalente a 2SM gastam em média entre 30\% e $25 \%$ da renda com alimentação em domicilio e $5 \%$ com alimentação fora do domicilio. Isso se reflete no baixo peso desse grupo de famílias até 2SM no mercado de alimentação fora de casa, em que em 2008/2009 representava apenas 6\% do mercado. Para uma discussão mais detalhada entre o salário mínimo e seu impacto sobre os rendimentos do setor informal, agrícola, etc. da economia, ver Medeiros (2015a) e Summa e Serrano (2015).

(16) Na verdade, Summa e Braga (2014) encontram uma relação negativa entre demanda por alimentos e inflação, e uma causalidade invertida na relação (inflação dos alimentos reduz o crescimento das vendas no varejo).

(17) Carvalho (2016) estima um modelo VAR para o período 2005-2013 para avaliar a relação entre salário médio e inflação dos serviços, e encontra que esta variável é relevante para explicar a inflação dos serviços. A autora então testa os modelos VAR controlados por variáveis de demanda (Hiato do produto etc.) e variáveis de produtividade, e seus resultados sugerem que a inflação do setor serviços está mais associado a uma pressão pelos custos, do que a pressões de demanda. 
Levando em conta todos esses fatores, esse nos parece o mecanismo menos provável para explicar o canal de transmissão do salário mínimo para a inflação na economia brasileira recente.

O segundo possível canal de transmissão decorre do fato de que a própria cesta de bens e serviços do IPCA do Brasil inclui alguns preços completamente (ou bastante) intensivos em trabalhos de qualificação mais baixa, que sofrem forte influência direta do salário mínimo. Assim, segundo nossa equação, ela levaria em conta o peso desses serviços no IPCA, $c\left(1-\theta_{S}\right)$, bem como a magnitude do aumento real do salário mínimo $\sigma_{0 t}$. Segundo Martinez (2014) cerca de 5,2\% do IPCA corresponde aos preços dos serviços "trabalhador doméstico" e "cabeleireiro, manicure, barbeiro e depilação". Em um outro estudo Botelho (2015) mostra que sete itens cointegram com a evolução do salário mínimo e que estes itens equivalem a $24 \%$ do IPCA de serviços (e o grupo serviços equivale a cerca de $35 \%$ do IPCA): Condomínio, Mudança, Manicure, Cabeleireiro, Depilação, Mão-de-obra para reforma de imóvel e empregado doméstico.

Esse canal de transmissão do salário mínimo para a inflação parece funcionar bem a partir de 2006, quando alguns preços de serviços livres como "empregado doméstico", "depilação", e em um grau um pouco menor "costureira" e "manicure e pedicura", seguiram a evolução do salário mínimo conforme pode ser visto no Gráfico 2. Porém, como pode ser visto no Gráfico 1, antes de 2006 esses preços cresceram muito menos que o salário mínimo.

\section{Gráfico 1}

Salário mínimo e itens de serviços sensíveis ao mínimo desde 2000 (índice)

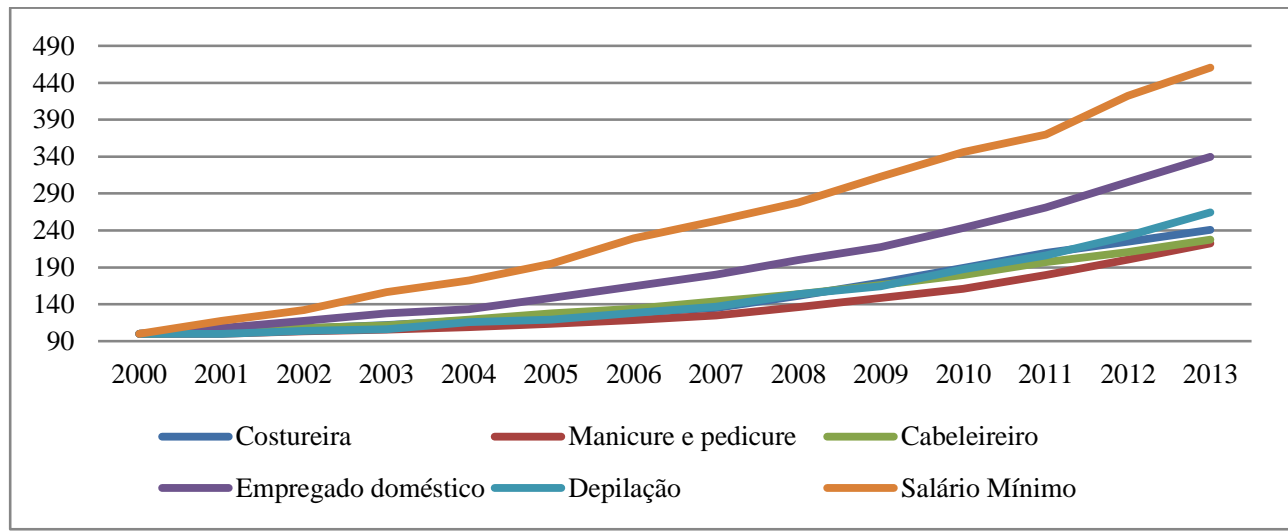

Fonte: IPCA (Sidra), TEM. 
Gráfico 2

Salário mínimo e itens de serviços sensíveis ao mínimo desde 2006 (índice)

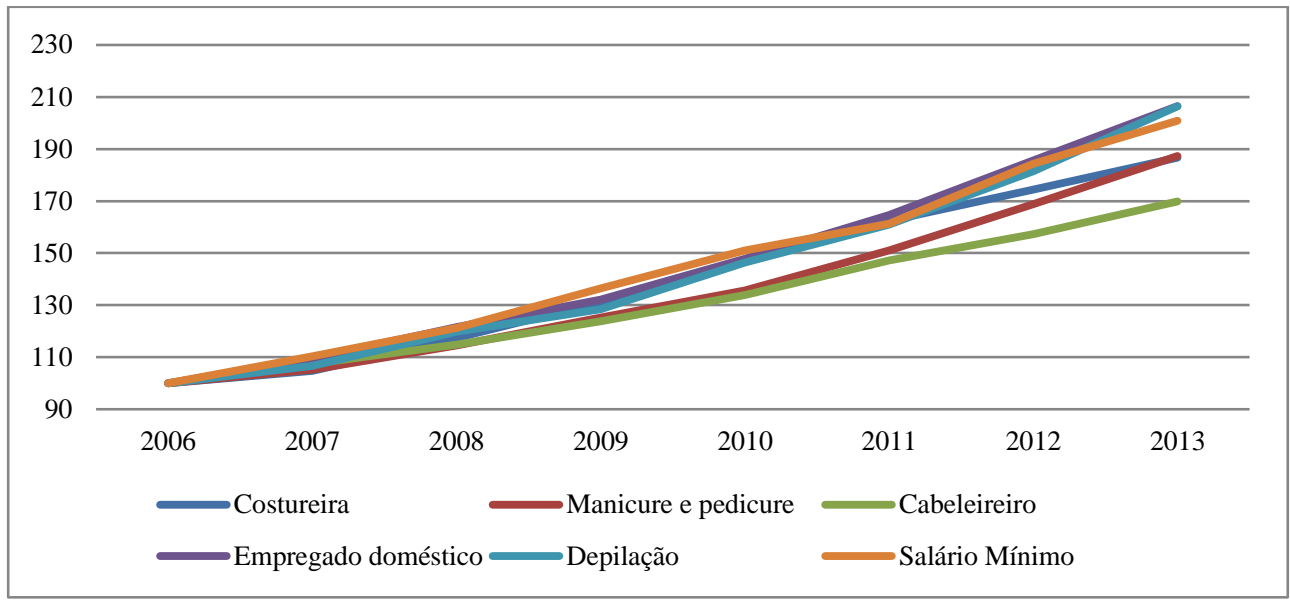

Fonte: IPCA (Sidra), TEM.

O terceiro possível efeito ocorreria pela influência da variação do salário mínimo sobre a variação do salário médio, e via custos dos bens livres não comercializáveis, sobre a inflação.

Uma relação direta entre choques do salário mínimo na inflação em nossa equação (24) ocorreria via parâmetros contidos em $X$ bem como do ganho real do salário mínimo $\sigma_{0 t}$. Medeiros (2015b) mostra que o salário mínimo é cada vez mais relevante para o salário médio, ao afetar pisos salariais urbanos e industriais e também os salários do setor agrícola e outros. Além disso, ainda segundo Medeiros (2015b), o salário mínimo é cada vez mais importante para a taxa de salários, uma vez que a proporção entre salário mínimo e médio aumentou recentemente (ver também Botelho, 2015).

Olhando para o Gráfico 3 notamos que a relação entre salário mínimo e salário médio não apresenta, pelo menos a primeira vista, uma relação tão clara de correlação. Até 2005, a despeito do aumento do salário mínimo real, o salário médio real teve crescimento negativo na maioria dos anos. Porém, a partir de 2006, o salário mínimo real continuou crescendo em torno de $5 \%$ e o salário médio abaixo disso, em torno de $3 \%$, mostrando que, mesmo que exista essa relação mais sistemática, a partir de 2006 o repasse do salário mínimo para o médio é parcial. Borges (2015) estima um modelo VAR para o período 2000-2013 e mostra que os reajustes do salário mínimo têm impacto estatisticamente significante e positivo sobre salários, porém "a elasticidade é bem pequena" (p. 280). 
Gráfico 3

Relação entre crescimento do Salário mínimo e do salário médio real

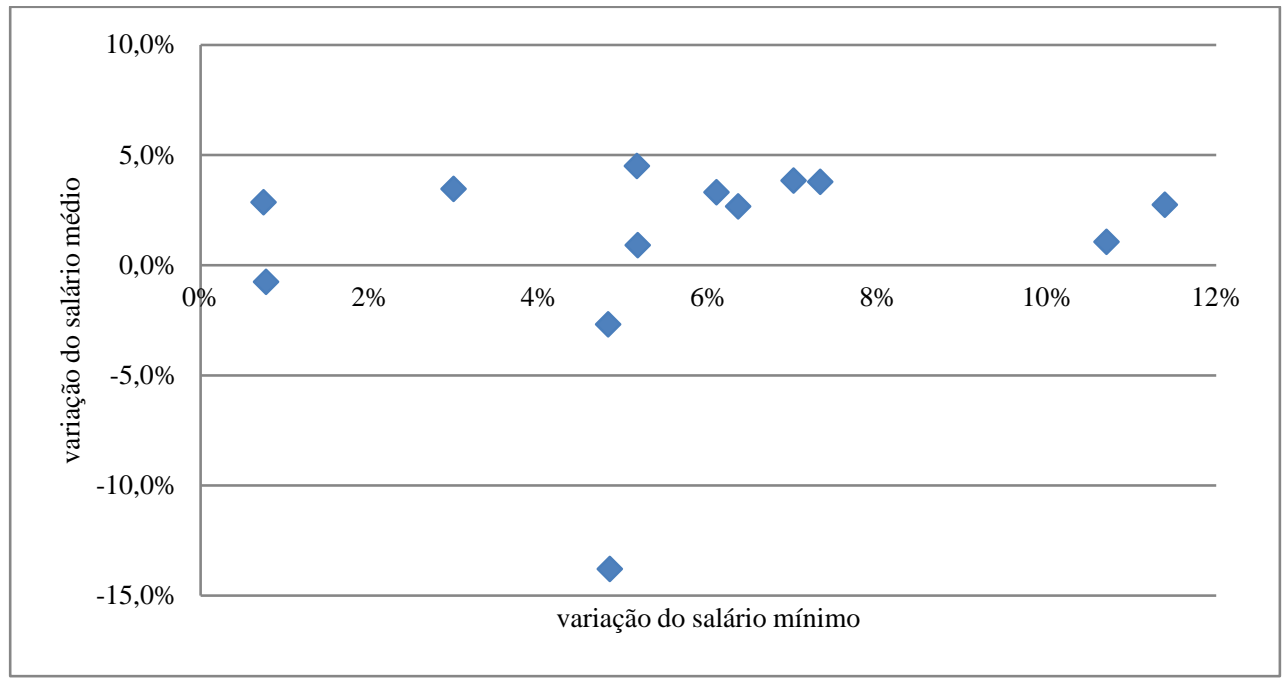

Fonte: CAGED, IPCA-IBGE, TEM.

Poderíamos assim concluir que a relação entre salário mínimo e inflação não é tão forte, a partir dos três canais de transmissão diretos do salário mínimo sobre a inflação discutidos acima e dos estudos empíricos apresentados na seção 1. Porém, argumentaremos que pode haver uma relação mais indireta entre salário mínimo e inflação.

Para discutir a possível relação mais indireta entre a política de salário mínimo e a inflação, levaremos em conta o papel que a política de salário mínimo pode ter sobre fatores institucionais e políticos que afetam o poder de barganha dos trabalhadores em negociar seus reajustes salariais. Em nossa equação 24, esse efeito aparece no fator $\psi_{t}$, capaz de aumentar os salários nominais de maneira autônoma e na relação entre desemprego e inflação.

No caso do Brasil, a política do salário mínimo pode ter impactado de maneira indireta no grau do poder de barganha dos trabalhadores em negociar seus salários reais. Isso porque essa política tem efeitos sobre outras políticas sociais e institucionais (por exemplo, previdência, seguro-desemprego, abono salarial). Além disso, essa medida foi tomada em conjunto com outras políticas sociais (ex. bolsa família) e a uma situação conjuntural favorecida do mercado de trabalho, com aumento da formalização e uma taxa de desemprego tendencialmente em queda e, nos últimos anos, em patamares baixos por um período considerável. Essa situação, como argumentamos anteriormente, é decorrente de uma melhora de uma série de componentes da demanda agregada (muitos deles não vinculados ao salário mínimo), 
que gerou um crescimento indutor do emprego formal por uma configuração setorial particular (forte criação de empregos em setores como construção civil, comércio e serviços) ao passo que teve um crescimento mais lento do tamanho da força de trabalho (por motivos demográficos mas também pela melhora das políticas sociais $)^{18}$.

Todos esses fatores tomados em conjunto parecem ter despertado algum poder de barganha dos trabalhadores, que passaram a realizar maior número de greves, a conseguir mais acordos coletivos e de progressivamente conseguirem reajustes reais para a maioria dos trabalhadores (Summa, 2015; Dieese, 2015).

O Gráfico 4 demonstra o aparecimento dessa inflação salarial mais resistente, que começa a crescer em média 3\% em termos reais a partir de 2006, a despeito da taxa de desemprego ainda se situar em um patamar alto de $10 \%$ (mesmo utilizando os dados da PME/IBGE). Esse crescimento dos salários é relativamente estável em torno dessa média e a situação de um desemprego diminuindo e alcançando patamares mais baixos ajuda a manter esse processo e reforçar o poder de barganha dos trabalhadores.

\section{Gráfico 4}

Crescimento do Salário médio real e taxa de desemprego

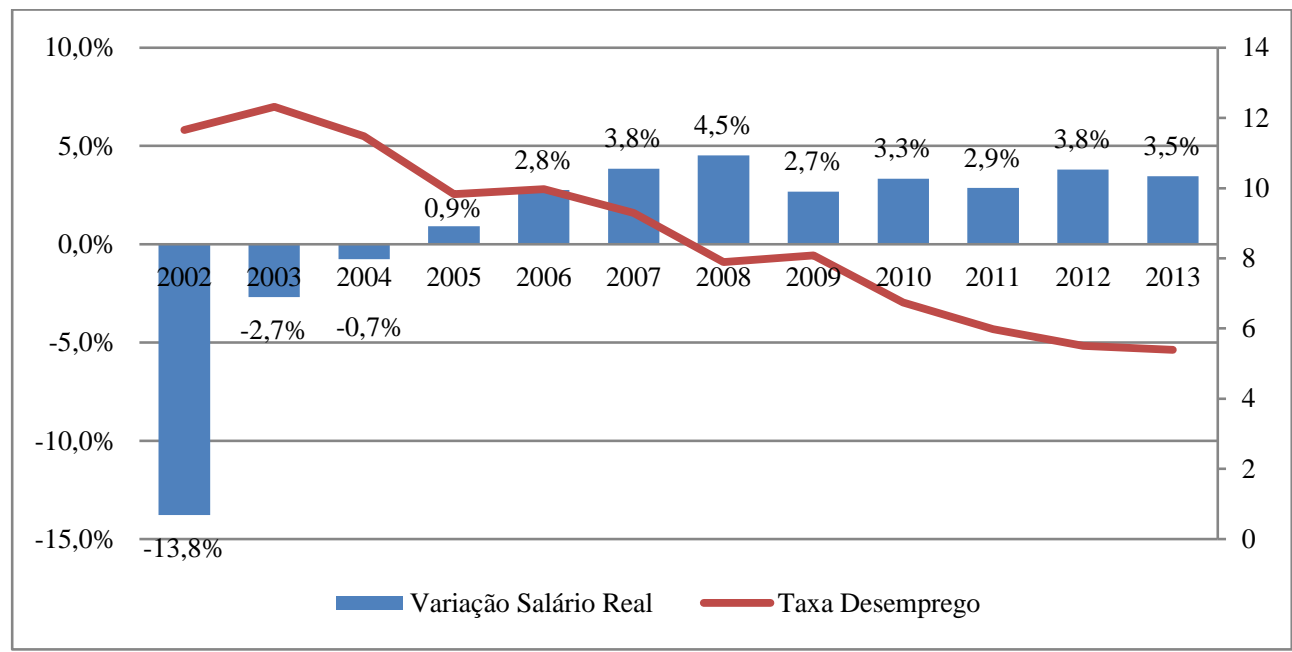

Fonte: CAGED, IPCA-IBGE, PME-IBGE.

Por fim, esse canal de transmissão do salário mínimo para o salário médio, tanto pelo efeito direto quanto indireto, só irá impactar a inflação da economia também sob mediação de alguns aspectos setoriais. $\mathrm{O}$ repasse da inflação salarial

(18) Ver Summa e Serrano (2015). 
para a inflação dos preços depende da competição externa e do aumento da produtividade, e esses fatores são diferentes para os setores desagregados da economia. Os gráficos 5 a 7, abaixo, mostram a relação entre variação dos preços e salários nos três setores da economia.

Gráfico 5

Inflação dos salários da agropecuária e dos preços dos alimentos (acumulado em 12 meses)

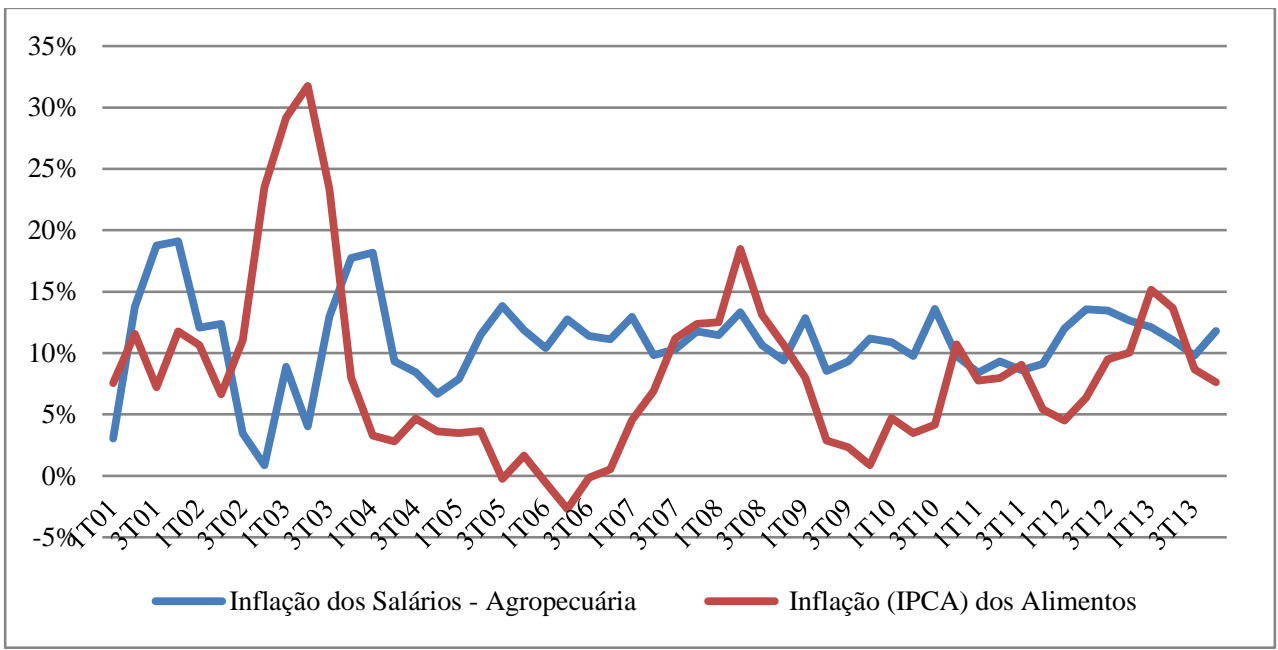

Fonte: Martinez (2014); CAGED.

Gráfico 6

Inflação dos salários da indústria de transformação e dos preços dos bens industriais (acumulado em 12 meses)

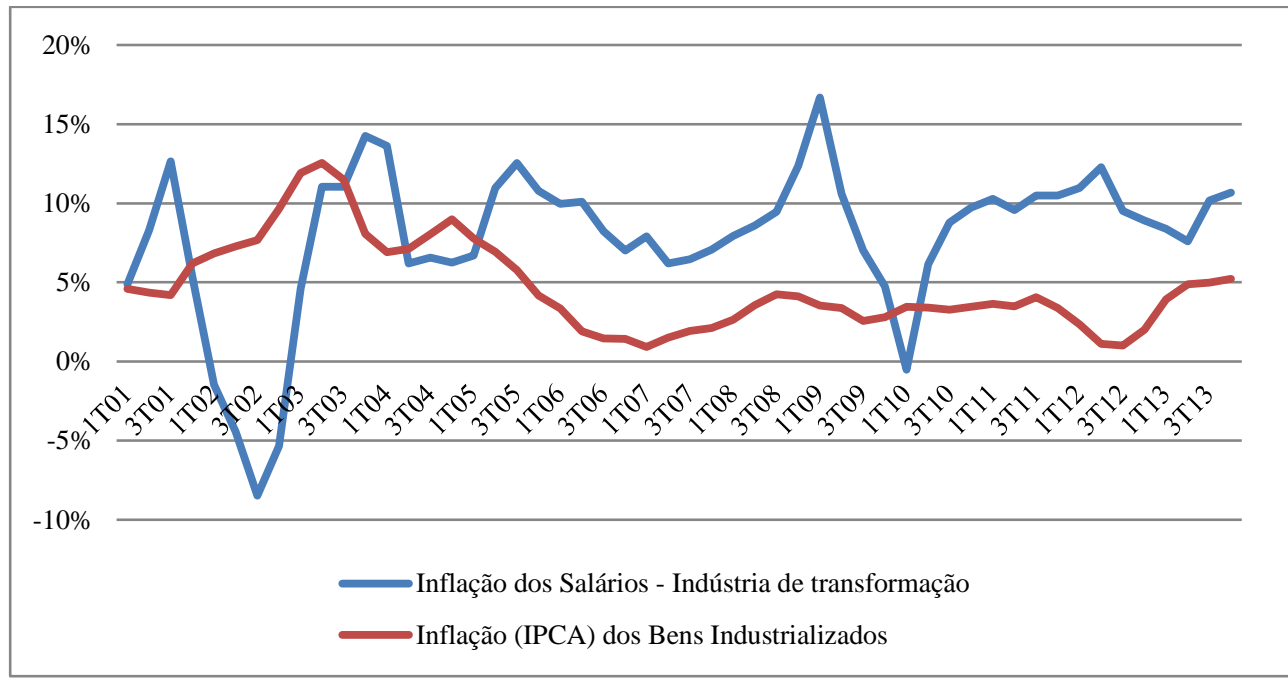

Fonte: Martinez (2014); CAGED. 
Gráfico 7

Inflação dos salários do setor de serviços e dos preços dos serviços (acumulado em 12 meses)

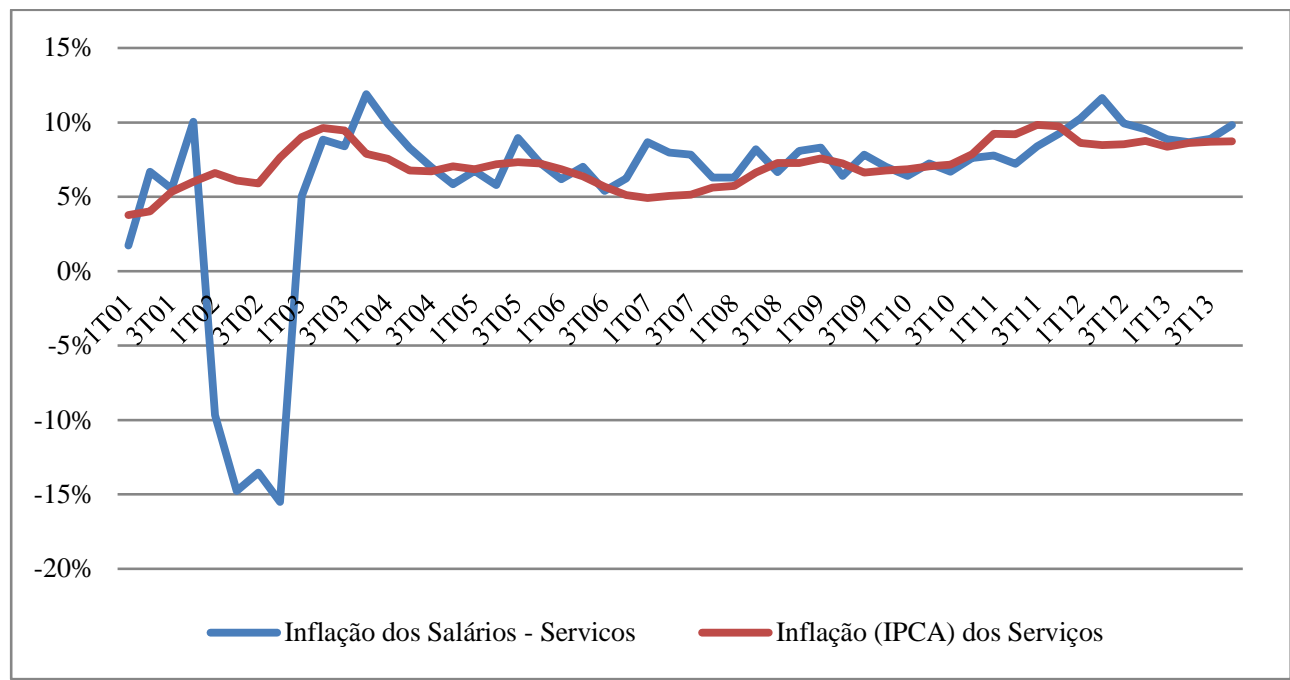

Fonte: Martinez (2014); CAGED.

Levando em conta os gráficos 5 a 7 e os dados de produtividade apresentados na Tabela 1, é possível concluir que o impacto do custo salarial é menor para os alimentos (alta produtividade agrícola e grande parcela de bens tradables) e para os bens industriais (grande parcela de bens tradables e forte concorrência externa, com algum ganho de produtividade) do que os serviços livres, uma vez que estes, além da alta parcela do componente salarial no custo total, não sofrem concorrência externa e não apresentam ganhos de produtividade muito baixos. (Dos Santos e outros, 2014 e Summa e Braga, 2014).

\section{Considerações finais}

O presente artigo discute a dinâmica da inflação brasileira no período 20002014 e sua relação com a política de valorização do salário mínimo, a partir de um modelo desagregado de inflação de custo. Os possíveis canais de transmissão que levariam a uma relação entre salário mínimo e inflação são analisados à luz dos dados brasileiros. Os poucos estudos sobre o tema e os dados analisados mostram que choques no salário mínimo não produzem impacto tão significativo sobre a inflação. Assim, os canais que estabelecem uma relação mais direta entre inflação e salário mínimo - via demanda agregada e consumo privado, salários em serviços intensivos em trabalho de qualificação mais baixa, ou via variação do salário médio - não parecem ser capazes de estabelecer uma relação forte e sistemática entre essas duas variáveis. 
Porém, isso não quer dizer que a política de valorização do salário mínimo tenha um papel tão reduzido em explicar a inflação brasileira recente. Argumentouse no artigo que a política de salário mínimo, em conjunto com outras políticas institucionais e aspectos conjunturais do mercado de trabalho, melhoraram o poder de barganha dos trabalhadores e foram responsáveis pelo surgimento de uma inflação salarial mais resistente, a partir de 2006. Esse efeito indireto do salário mínimo se mostrou importante para explicar a dinâmica inflacionária em nossa argumentação. Assim, dentro desse ponto de vista, a política de valorização do salário mínimo constitui um elemento importante para explicar a inflação salarial e a inflação ao consumidor, ainda que outras políticas institucionais e elementos conjunturais tenham contribuído para reforçar esta relação.

\section{Bibliografia}

AIDAR, G. The New Keynesian Phillips curve: a critical assessment. In: DISTRIBUTION and Aggregate Demand, First Young Researchers. Workshop of Theoretical and Applied Studies in Classical Political Economy. Roma: Tre University. 2012.

AMITRANO, C. Liderança, dinamismo e comando: uma análise setorial do mercado formal de trabalho brasileiro. In: SQUEFF, G. Dinâmica macrossetorial brasileira. Brasília: Ipea, 2015.

BALL, L.; MOFFITT, R. Productivity growth and the Phillips curve. Cambridge: National Bureau of Economic Research, 2001.

BARBOSA, N.; PESSOA, S.; MOURA, R. Política de salário mínimo para 2015 2018: avaliações de impacto econômicos e sociais. Rio de Janeiro: Elsevier, FGV, 2015.

BASTOS, C.; JORGE, C.; BRAGA, J. Análise desagregada da inflação por setores industriais da economia brasileira entre 1996 e 2011. Revista de Economia Contemporânea, v. 19, n. 2, p. 261-279, 2015.

BCB - BANCO CENTRAL DO BRASIL. Algumas evidências sobre a relação entre salário e inflação no Brasil. Relatório de Inflação, Brasília, v. 15, n. 1, mar. 2013.

BLANCHFLOWER, D.; OSWALD, A. The wage curve reloaded. Cambridge: NBER, 2005. (Working Paper, n. 11338).

BORGES, B. Salários e inflação no Brasil: uma análise desagregada. Apresentação. In: BARBOSA, N.; PESSOA, S.; MOURA, R. (Org.). Política de salário mínimo para 2015-2018: avaliações de impacto econômicos e sociais. Rio de Janeiro: Elsevier, FGV, 2015. 
BOTELHO, V. Inflação e salário mínimo: efeitos sobre o custo dos serviços. In: BARBOSA, N.; PESSOA, S.; MOURA, R. (Org.). Política de salário mínimo para 2015-2018: avaliações de impacto econômicos e sociais. Rio de Janeiro: Elsevier, FGV, 2015.

BRAGA, J. A inflação brasileira na década de 2000 e a importância de políticas não monetárias de controle. Economia e Sociedade, Campinas, v. 22, n. 3 (49), p. $697-$ 727, dez. 2013.

BRESSER PEREIRA, L. Fatores aceleradores, mantenedores e sancionadores da inflação. Revista de Economia Política, v. 4, n.1, jan./mar. 1984.

BRESSER PEREIRA, L. A descoberta da inflação inercial. Revista de Economia Contemporânea, v. 14, n. 1, 2010.

CARLIN, W.; SOSKICE, D. Macroeconomics: imperfections, institutions, and policies. Oxford: OUP Catalogue, 2005.

CARVALHO, L. Income distribution, structural change and service inflation in Brazil. Economia (Anpec), forthcoming, 2016.

DIEESE. Balanço das greves em 2013. Estudos e Pesquisas, n. 79, dez. 2015.

DÓRIA, R. Evolução do padrão de consumo das famílias brasileiras no período 2003-2009 e relações com a distribuição de renda. Dissertação (Mestrado-IEUFRJ, 2013.

Dos SANTOS, C. H. Notas sobre as dinâmicas relacionadas do consumo das famílias, da formação bruta de capital fixo e das finanças públicas brasileiras no período 2004-2012. In: CORREA, V. P. (Org.). Padrão de acumulação e desenvolvimento brasileiro. São Paulo: Editora Fundação Perseu Abramo, 2013.

Dos SANTOS, C. H.; AMITRANO, C.; CASTRO-PIRES, M.; CARVALHO, S.; FERREIRA, E.; ESTEVES, F.; YANNICK, K. ; LIMA, L. A natureza da inflação de serviços no Brasil: 1999-2014. Brasília: Ipea, 2014. Mimeografado.

FEVEREIRO, J.; FREITAS, F. Produtividade do trabalho e mudança estrutural: uma comparação entre diferentes métodos de decomposição a partir da experiência brasileira entre 2000-2011. Rio de Janeiro: IE-UFRJ, 2015. Mimeografado.

GAREGNANI, P. Sraffa: classical versus marginalist analysis. Essays on Piero Sraffa: critical perspectives on the revival of classical theory. London: Unwin Hyman, 1990. p. 112-141.

GAREGNANI, P.; CAVALIERI, T. \& LUCII, M. Full employment and the left. In: BINI, P.; TUSSET G. (Org.). Theory and practice of economic policy. Tradition and change. Selected Papers from the 9th Aispe Conference. Milan: Franco Angeli Edizioni, 2008. 
GLYN, A. Capitalism unleashed: finance, globalization, and welfare. Oxford: Oxford University Press, 2006.

KALECKI, M. Political aspects of full employment. The Political Quarterly, v. 14, n.4, p. 322-330, 1943.

KALECKI, M. Class struggle and the distribution of national income. Kyklos, v. 24, n. 1, p. 1-9, 1971.

LARA REZENDE, A.; LOPES, F. Sobre as causas da recente aceleração inflacionaria. Pesquisa e Planejamento Econômico, v. 11, n. 3, p. 599-616, 1981.

LEMOS, S. Minimum wage effects on wages, employment and prices: implications for poverty alleviation in Brazil. Leicester, RU: University of Leicester, 2005.

LEMOS, S. A survey of the effects of the minimum wage on prices. Journal of Economic Surveys, v. 22, n. 1, p. 187-212, 2008.

LERNER, A. Economics of employment. New York: McGraw-Hill Company, 1951.

MARTINEZ, T.; CERQUEIRA, V. (2013). Estrutura da inflação brasileira: determinantes e desagregação do IPCA. Economia e Sociedade, v. 22, n. 2, p. 409456, 2015.

MARTINEZ, T.; BRAGA, J. Crescimento liderado pelos salários, política monetária e inflação no Brasil. In: ENCONTRO DA AKB, 5, São Paulo, 2012.

MARTINEZ. T. S. Compatibilização de mudanças em classificações desagregadas do IPCA (1999-2014). Brasília: Ipea, 2014. (Texto para Discussão). No prelo.

MEDEIROS, C. Inserção externa, crescimento e padrões de consumo na economia brasileira. Brasília: Ipea: 2015a.

MEDEIROS, C. A influência do salário mínimo sobre a taxa de salários no Brasil na última década. Economia e Sociedade, v. 24, n. 2, p. 263-292, 2015 b.

MODIANO, E. A dinâmica de salários e preços na economia brasileira: 1966/81. Pesquisa e Planejamento Econômico, v. 13. n. 1, p. 39-68, 1983.

MODIANO, E. Salários, preços e cambio: os multiplicadores dos choques numa economia indexada. Pesquisa e Planejamento Econômico, v. 15, n. 1, 1985.

ORAIR, R.; GOBETTI, S. Governo gastador ou transferidor? Um macrodiagnóstico das despesas federais no período de 2002 a 2010. In: IPEA. Brasil em desenvolvimento. Brasília: Ipea, 2010. v. 1, p. 87-112.

PHILLIPS, A. W. The relation between unemployment and the rate of change of money wage rates in the United Kingdom, 1861-1957, Economica, 25, p. 283-299, 1958. 
PALUMBO, A. From zero to 20 percent: a historical account of the empirical measure of unemployment corresponding to 'full employment'. Paper presented at the ESHET Conference 2015, RomaTre University, May 2015.

POLLIN, R. Wage bargaining and the US Phillips Curve: was Greenspan right about traumatized workers in the 90s? Amherst: Political Economy Research Institute, University of Massachusetts, 2002. Mimeografado.

ROWTHORN, R. E. Conflict, inflation and money. Cambridge Journal of Economics, v. 1, n. 3, p. 215-239, 1977.

SERRANO, F. Inflação inercial e desindexação neutra. In: REGO, J. M. (Org.). Teorias da inflação inercial e plano cruzado. Rio de Janeiro: Paz e Terra, 1986.

SERRANO, F. O conflito distributivo e a teoria da inflação inercial. Revista de Economia Contemporânea, 2010.

SERRANO, F.; SUMMA, R. Macroeconomic policy, growth and income distribution in the Brazilian economy in the 2000s. Investigación Económica, p. 5592, 2012.

SERRANO, F.; SUMMA, R. Aggregate demand and the slowdown of Brazilian economic growth from 2011-2014. Washington DC: Center for Economic and Policy Research, 2015.

STIRATI, A. The theory of wages in classical economics: a study of Adam Smith, David Ricardo, and their contemporaries. Cheltenham, United Kingdom: Edward Elgar Publishing, 1994.

STIRATI, A. Inflation, unemployment and hysteresis: an alternative view. Review of Political Economy, v. 13, n. 4, p. 427-451, Oct. 2001.

STIRATI, A. Real wages in the business cycle and the theory of income distribution: an unresolved conflict between theory and facts in mainstream macroeconomics. Cambridge Journal of Economics, p. beu088, 2015.

SUMMA, R. Uma avaliação crítica das estimativas da curva de Phillips no Brasil. Pesquisa \& Debate. Revista do Programa de Estudos Pós-Graduados em Economia Política, v. 22, n. 2 (40), 2011.

SUMMA, R. Mercado de trabalho e a evolução dos salários no Brasil. Revista da Sociedade Brasileira de Economia Política, n. 42, 2015.

SUMMA, R.; MACRINI, L. Os determinantes da inflação brasileira recente: estimações utilizando redes neurais. Nova Economia, v. 24, n. 2, p. 279-296, 2014.

SUMMA, R.; BRAGA, J. Estimação de um modelo desagregado de inflação de custo para o Brasil. Rio de Janeiro: IE-UFRJ, 2014. (Texto para Discussão, n. 14). 
SUMMA, R.; SERRANO, F. Distribution and cost-push inflation in Brazil under inflation targeting, 1999-2014. Roma: Centro Sraffa, 2015. (Working paper, n. 14). SYLOS LABINI, P. (1979). Preços e distribuição de renda na indústria de transformação. In: LABINI, P. Ensaios sobre desenvolvimento e preços. São Paulo: Forense-Universitária, 1984.

SYLOS LABINI, P. Preços rígidos, preços flexíveis e inflação. In: LABINI, P. Ensaios sobre desenvolvimento e preços. São Paulo: Forense-Universitária, 1984. 